\title{
The Effects of Media and Peers on Negative Body Images of Chinese College Students: Multiple Mediating Effects of Appearance Comparison and Internalization of the Thin-Ideal
}

\author{
Jianting Shen \\ Hunan University of Science and Technology \\ Jinjun Chen ( $\sim$ jingjunchenpsy@163.com ) \\ HUNAN University of Science and Technology \\ Xiwen Tang \\ Hunan University of Science and Technology \\ Shangfei Bao \\ Hunan University of Science and Technology
}

\section{Research Article}

Keywords: Peer, Media, Appearance comparison, Internalization of the thin-ideal, Body image

Posted Date: November 15th, 2021

DOI: https://doi.org/10.21203/rs.3.rs-1059631/v1

License: (a) (i) This work is licensed under a Creative Commons Attribution 4.0 International License.

Read Full License 


\section{Abstract \\ Background}

Negative body image is a common psychological phenomenon among Chinese college students, which should arouse our attention. Peers and media are important factors that influence personal negative body image. This study explores the mechanism of media and peers on the negative body image of Chinese college students.

\section{Methods}

461 college students (173 identifying as male, 234 identifying as female) were investigated by using the Revised Social and Cultural Attitude Questionnaire of Appearance, Appearance Comparison Scale, Peer Impact Scale and Negative Body Image Scale.

\section{Results}

The results are as follows: (1) Correlation analysis shows that except media attention is not significantly correlated with negative body images, all other variables are significantly positively correlated; (2) Path analysis shows that the direct effect of media attention on negative body image is not significant, while the direct effect of peer impact is significant, and both of them have indirect effects through the mediate role of appearance comparison and internalization of the thin-ideal. Additionally, appearance comparison and internalization of the thin-ideal act as a chain mediation between negative body image and media attention, peer impact.

\section{Conclusions}

The research shows just paying attention to the information of the perfect body in the media will not produce negative body image, but paying attention to the media and peer talks about the body may cause college students to compare appearances and internalize the standards for a good shape, leading to their negative evaluation of themselves.

\section{Plain English Summary}

Peers and media have far-reaching influence on negative body image of individuals. The purpose of this study is to explore the influence of media and peers on negative body image of Chinese college students and its special mechanism. In this study, 461 Chinese college students were investigated by questionnaire. For Chinese college students, the results show that peer impact can directly affect negative body image, but media attention can't. Accidentally, they can all produce negative body image through psychological activities such as appearance comparison and internalization of the thin-ideal. In addition, 
media attention and peer impact will further increase the negative evaluation of college students' figure through the chain mediation of "appearance comparison - internalization of the thin-ideal".

\section{Introduction}

Body image is defined as how an individual perceives his own body and how he perceives others' evaluations of his body. The negative body image refers to the individual's negative view of his own body and others' evaluation of his body. It is common among young people in China to express dissatisfaction with their body image.A survey of students from grade one of junior school to the fourth grade of university shows that the physical dissatisfaction of college students is the most prominent (Huang et al.,2002). In order to explain the effects of various factors on body image, a theory was proposed as a sociocultural model of physical satisfaction (Thompson et al.,1999). The hypothesis of sociocultural model is: firstly, sociocultural factors affect physical satisfaction, among which, family, peers and media are the three initial sources of physical satisfaction; Secondly, appearance comparison and internalization of the thin-ideal are mediate variables between social and cultural factors and physical satisfaction (Fig. 1).

This model is put forward in the western cultural background, and whether it is suitable for our Chinese cultural background needs further verification.Chinese culture is a collectivist culture with socially oriented psychology and behavior. Chinese people tend to compare with others, pay much attention to other people's thoughts and evaluations, and easily feel interpersonal pressure (Huang \& Zhang,2005). Compared with the West, Chinese people seem to care more about their own image (including appearance) in the eyes of others, which may lead to self-pursuit not meeting the actual high standards, and more easily lead to negative self-evaluation. This is quite different from the western individualistic culture. In China, most students have lived on campus since junior high school, and even some students have lived on campus since primary school. Moreover, college students have basically left their families and started to live on campus. Their life centers are mainly on campus, and their peers are the people who spend the most time with each other. Moreover, the study has shown that parents have little influence on an individual's body image (Shroff \& Thompson,2006), so this study only explores the influence of mass media and peers on negative body image.

\section{The effects of media and peers on negative body image}

Mass media refers to newspapers, magazines, television, radio, movies, books, audio-visual products, internet, and other media that disseminate social and cultural information. It is generally considered as an important factor affecting negative body image. The negative influence of media on body image has been confirmed by many researchers. Previous research reveals that that mass media has obvious negative influence on women's body images (Yang,2007). Myers and Biocca (1992) found that even watching advertisements or programs related to slimming for only one minute can change a woman's view of her self-body. Explaining from the perspective of perceived pressure in media information, women think that slim figure is closely related to personal attraction, and that career success, good interpersonal 
relationship and ideal object are inseparable from slim figure (Streigel-Moore \& Bulik,2007). According to the objectification theory (Fredrickson \& Roberts,1997), the media constantly portrays slim and slender female images, which will make women look at their physical self from a third-person perspective, and pay attention to observable physical attributes instead of what they can do. They take an attitude of examining and evaluating their body for a long time, which will lead to negative psychological or subjective experience. Another explanation is that adult individuals who are dissatisfied with their health have a cognitive bias towards health-related information (Jiang\& Vartanian, 2012; Rodgers \& DuBois,2016; Uusberg, Peet et al., 2018), and there mainly are attention bias, memory bias and explanation bias. Frequent exposure to the standard of "unrealistic ideal body shape" conveyed by the media may affect the way of individuals processing body-related information, and make it easier for individuals to form negative body images (Rodgers \& DuBois, 2016). Therefore, this study puts forward Hypothesis1: College students' media attention positively predicted negative body images.

College students' social circle is mainly on campus, and their peers are the main social objects. The communication with their peers will affect their attention to appearance information, the formation of ideal body shape standards and the development of body images (Webb et al., 2015). Peer impact in this study refers to the influence of peer's talk, evaluation and even ridicule on body appearance. Talking about obesity among women (a kind of communication that often occurs in women's friendship groups and focuses on topics such as size, weight and eating habits) will have a negative impact on the cognition of body image (Wu et al., 2016). Studies have shown that peer ridicule is an important predictor of physical dissatisfaction (Lawler \& Nixon, 2011). Therefore, this study puts forward Hypothesis 2: Peer impact of college students positively predict negative body images.

\section{The Mediate Role of Appearance Comparison}

Mass media is an important way to spread sociocultural standards and social expectations such as ideal size, weight and fashion. With the rapid development of the times, more and more college students can get in touch with the pictures and speeches of the mass media to promote the ideal body figure. According to social comparison theory, social comparative motivation with the whole process of physical attention is the main factor of physical dissatisfaction (Durkin \& Paxton,2002). When individuals observe other perfect bodies, they will have upward comparative psychology and self-evaluation motivation, and then produce negative body images. Therefore, this study puts forward Hypothesis 3: Appearance comparison plays a mediate role between media attention and negative body images.

Compared with childhood, teenagers will pay more attention to their appearance and image, and pay more attention to other people's evaluation of themselves, and are very sensitive to their external "shortcomings" or "imperfections". Peers' ridicule on their appearance will further deepen teenagers' understanding of their "imperfections" (Eisenberg et al., 2006). Studies have shown that female college students' involvement in obesity reviews can positively predict female college students' negative physical self (Liu,2021). According to the theory of social comparison, when an individual hears negative comments or talks about his own figure, he will have upward comparative psychology and self-evaluation motivation (Xing \&Yu,2004). The negative comments on peers' figure stems from the fact that peer 
groups have a standard of "perfect figure". Poor evaluation forces them to compare with "perfect figure", thus producing more negative body images. Therefore, this study puts forward Hypothesis 4: Appearance comparison plays a mediate role between peer impact and negative body images.

\section{The Mediate Role of Internalization of the Thin-ideal}

Today, "thinness is beauty" has become the aesthetic standard of most people, leading to more and more people dissatisfied with one's body shape, resulting in negative body image. "Be thin or die" has become the motto of many young women today. Internalization of the Thin-ideal is the process of adopting social perfect body image as personal goal and standard. College students are eroded by the definition of "perfect figure" by mass media for a long time, and may constantly internalize the social perfect appearance standard. A research result show that female viewers will increase their immediate physical dissatisfaction after watching music TV programs with slim female images (Tiggenmann \& Slater,2004). Other studies have shown that the higher the female internalization level of the "ideal thin" female model image in fashion magazines, the stronger the negative body image of female college students (Tang, 2010). The development of internalization research also shows that repeated "exposure" under the visual image of "ideal thin" model will lead to higher internalization level, which will lead to physical dissatisfaction (Stice et al.,1994; Stice, Ziemba et al., 1996). Internalization plays an "initiating" and mediating role between sociocultural influences and negative body images of women and their subsequent behaviors. Therefore, this study puts forward Hypothesis 5: Internalization of the thin-ideal plays an mediate role between media attention and negative body images.

Peer talk about body will constantly strengthen the social standard of perfect body, and then change the individual's view of body. According to a research result (Huang \& Zhang,2005), the viewpoint that "thinness is beauty" is often adopted in the evaluation of body size in various interpersonal relationships, and the social pressure thus formed has a significant impact on individual body images. On the other hand, from the perspective of social learning process, once an individual accepts the evaluation of his body figure from his peers, it will be internalized into his own views and attitudes towards his own body, thus affecting his body image. A longitudinal study of adolescent boys and girls showed that internalization also played an mediate role between peer appearance talk and physical dissatisfaction (Jones,2004). Therefore, this study puts forward Hypothesis 6: Internalization of the thin-ideal plays a mediate role between peer impact and negative body images.

\section{A Multiple Mediate Model}

As for the two mediating variables in this study, namely, appearance comparison and internalization of the thin-ideal, according to social comparison theory, appearance comparison can positively predict internalization of the thin-ideal. Appearance comparison means that an individual compares himself with the image of "ideal thinness" spread in the media. In the process of comparison, the individual is constantly accepting the ideal body shape promoted by the mass media, and then gradually internalizes the standard of ideal thinness. Therefore, college students' exposure to the "ideal thinness" disseminated by the mass media will lead to their appearance comparison behavior, and then gradually internalize 
social standards, which will eventually produce negative body images. Therefore, this study puts forward Hypothesis 7: Appearance comparison and internalization of the thin-ideal play a chain mediating role between media attention and negative body images.

Nowadays, more and more college students will upload their selfies to their social platforms and receive comments on their appearance from peers or others, among which some negative comments on their appearance may be received. Negative appearance comments refer to intentional or unintentional harmful comments (such as "you look a little fatter in that dress"). According to the theory of social comparison, this will virtually make us contrast with a better body shape, and then internalize the "better" standard, which is difficult for us to achieve ourselves, and finally induces a more negative body image. Based on this study, hypothesis 8 is put forward: Appearance comparison and internalization of the thinideal play a chain mediating role between peer impact and negative body image. To sum up, this study intends to explore the relationship between college students' media attention, peers and negative body images, and the multiple mediating effects between appearance comparison and internalization of the thin-ideal.

\section{Methods}

\section{Participants}

By convenient sampling, 461 questionnaires were distributed in a university in Hunan (China), and 407 valid questionnaires were recovered, with an effective recovery rate of $88.29 \%$. There are 173 boys (42.5\%), 234 girls (57.4\%), 125 freshmen (30.7\%), 97 sophomores (23.8\%), 79 juniors (19.4\%) and 106 seniors (26.0\%). The average age was 20.23 years, and the standard deviation was 1.61 .

\section{Measures}

\section{Media Attention and Internalization of the Thin-ideal}

Media attention and internalization of the thin-ideal was measured using The Sociocultural Attitudes Towards Appearance Scale-3 (Liu,2009). There are 15 items in the scale, including two subscales, namely, Media Attention Subscale (questions 1-6, e.g., "I pay attention to the information related to personal attractiveness in magazines.") and Internalization Subscale (questions 7-15, e.g., "I hope my body looks like the people in the movies."). The second, fifth, sixth, tenth and eleventh subscales are reverse scoring questions, and the five-point scoring method is adopted, from "totally inconsistent" to "completely consistent". The higher the score, the higher the degree of internalization and media attention. The Kehlenbach's coefficient of the scale is 0.89 .

\section{Peer Impact}

Peer impact was measured using Peer Impact Scale in the Tripartite Influence Scale (Thompson et al.,2004). The scale consists of 13 items, which are translated and revised into 12 items. Use 5 points, from "never" to "always". The higher the score, the greater the negative influence of peers (e.g., "Have your 
friends or classmates ever commented or laughed at your appearance?"). The Kehlenbach's coefficient of the scale is 0.89 .

\section{Appearance comparison}

Appearance comparison was measured using the Appearance Comparison Scale (Chen, 2007) (Chinese version). There are 5 items in the scale. Five points are used, ranging from "never" to "always". The higher the score, the higher the individual's social comparative tendency (e.g., "At parties or other social activities, I will compare my appearance with that of others."). The Kehlenbach's coefficient of the scale is 0.77 .

\section{Negative body image}

Negative body image was measured using the Negative Body Image Scale (Chen et al.,2006). There are 27 items in the scale, including 4 factors: whole, fat, appearance and short. The number of items is 3, 9, 7 and 8, respectively, and the second, third, eleventh, twenty-third and twenty-seventh items are called reverse scoring questions. A five-point score is used, from "totally inconsistent" to "completely consistent". The higher the score, the more dissatisfied the individual is with his body image (e.g., "I'm worried about my appearance."). The Kehlenbach's coefficient of the scale is 0.84 .

\section{Data collection and statistical analysis}

SPSS 24.0 and AMOS 26.0 software were used to describe statistics, correlation analysis and path analysis.

\section{Results}

\section{Preliminary Analyses}

Harman's single factor analysis was used to test the deviation of the common method (Xiong et al., 2012). The results show that there are 11 factors with eigenvalues greater than 1 without rotation, which explain $66.94 \%$ of the variation, and the first factor explains $26.36 \%$ of the variation, which is less than the standard recommended by predecessors: $30 \%$. Therefore, there is no serious common method deviation in this study.

Except that media attention is not significantly related to negative body image, other variables are significantly positively related (Table 1 ). 
Table 1

Descriptive and correlations for variables

\begin{tabular}{|c|c|c|c|c|c|c|}
\hline Variable & $M \pm S D$ & 1 & 2 & 3 & 4 & 5 \\
\hline 1Media attention & $3.21 \pm 0.73$ & 1 & & & & \\
\hline 2Peer impact & $3.04 \pm 0.69$ & $0.152^{* \star}$ & 1 & & & \\
\hline 3Appearance comparison & $2.88 \pm 0.84$ & $0.168^{* *}$ & $0.423^{\star \star}$ & 1 & & \\
\hline 4Internalization of the thin-ideal & $2.89 \pm 0.72$ & $0.350^{* \star}$ & $0.328^{* *}$ & $0.532^{\star \star}$ & 1 & \\
\hline 5Negative body image & $2.57 \pm 0.62$ & 0.093 & $0.377^{\star \star}$ & $0.420^{* *}$ & $0.479^{\star \star}$ & 1 \\
\hline
\end{tabular}

\section{Main Analyses}

Based on the previous studies and the analysis of the relationship between variables, this study established a multiple mediation model, and investigated the mediate role of appearance comparison and internalization of the thin-ideal in the relationship between media attention, peer impact and negative body image. The fitting index of this model is $\chi^{2}=4.138, \chi^{2} / \mathrm{df}=4.138, \mathrm{NFI}=0.99, \mathrm{CFI}=0.99, \mathrm{IFI}=0.99$, RMSEA $=0.08$, indicating that the model is well adapted and acceptable.

The results show that the direct effect (Fig. 2) between media attention and negative body image is not significant, while the direct effect between peer impact and negative body image is significant. The mediating effects of appearance comparison and internalization of the thin-ideal are significant, and the chain mediating effects from media attention to negative body image and peer impact to negative body image are also significant. It shows that appearance comparison and internalization of the thin-ideal play multiple mediating roles among media attention, peer impact and negative body image.

The path coefficient (Fig. 2) shows that media attention is negatively correlated with negative body image, positively predicting appearance comparison $(\beta=.11, p<.05)$ and internalization of the thin-ideal $(\beta=.26, p<.001)$. Peer impact positively predicted negative body image $(\beta=.20, p<.001)$ and appearance comparison $(\beta=.41, p<.01)$. Compare appearance with positive prediction of negative body image ( $\beta$ $=.16, p<.05)$ and internalization of the thin-ideal $(\beta=.45, p<.001)$; internalization of the thin-ideal positively predicted negative body image $(\beta=.35, p<.001)$. 
Table 2

Bootstrap analysis of the significance of mediation effect

\begin{tabular}{|c|c|c|c|}
\hline \multirow[t]{2}{*}{ Path } & \multirow{2}{*}{$\begin{array}{l}\text { Estimate } \\
\text { (S.E.) }\end{array}$} & \multicolumn{2}{|c|}{$95 \% \mathrm{Cl}$} \\
\hline & & LL & UL \\
\hline Media attention $\rightarrow$ Appearance comparison $\rightarrow$ Negative body image & $0.017(0.010)$ & 0.003 & 0.046 \\
\hline $\begin{array}{l}\text { Media attention } \rightarrow \text { Internalization of the thin-ideal } \rightarrow \text { Negative body } \\
\text { image }\end{array}$ & $0.085(0.018)$ & 0.053 & 0.123 \\
\hline $\begin{array}{l}\text { Media attention } \rightarrow \text { Appearance comparison } \rightarrow \text { Internalization of the } \\
\text { thin-ideal } \rightarrow \text { Negative body image }\end{array}$ & $0.015(0.008)$ & 0.002 & 0.035 \\
\hline Peer impact $\rightarrow$ Appearance comparison $\rightarrow$ Negative body image & $0.065(0.024)$ & 0.021 & 0.115 \\
\hline $\begin{array}{l}\text { Peer impact } \rightarrow \text { Internalization of the thin-ideal } \rightarrow \text { Negative body } \\
\text { image }\end{array}$ & $0.033(0.017)$ & 0.004 & 0.068 \\
\hline $\begin{array}{l}\text { Peer impact } \rightarrow \text { Appearance comparison } \rightarrow \text { Internalization of the thin- } \\
\text { ideal } \rightarrow \text { Negative body image }\end{array}$ & $0.059(0.012)$ & 0.039 & 0.090 \\
\hline
\end{tabular}

Based on significant coefficient of direct path, the mediating effect is tested. Furthermore, the Bootstrap program of AMOS is used to test the significance of mediate effect. The confidence intervals corresponding to each path do not contain 0 (Table 2), which indicates that the indirect effects are significant. College students' appearance comparison and internalization of the thin-ideal have mediating effects among media attention, peer impact and Negative body image.

\section{Discussion}

This study investigates the effects of media attention and peers on negative body images, and the mediate mechanism of appearance comparison and internalization of the thin-ideal. The results show that peer impact significantly positively predicts negative body images of college students, and media attention and peer impact on negative body images has indirect effects through the mediation of appearance comparison and internalization of the thin-ideal. At the same time, appearance comparison and internalization of the thin-ideal play a chain mediate role between peer impact, media attention and negative body image.

Surprisingly, this study found that there was not a significant correlation between media attention and negative body image. Hypothesis 1 was not verified, but it was consistent with some research results. A study has shown that there is no inevitable relationship between the ideal thin image of media communication and low physical satisfaction (Gurari et al., 2006). Compared with the negative body image, the media has a more remarkable effect in spreading the positive body image (Crouch \& Degelman, 1998). The results of this study show that only paying attention to the information of perfect figure in mass media will not necessarily produce negative body images, which may be related to its 
internal mechanism. Media attention does not directly affect negative body images. Only when individuals compare themselves with the standards of the media and internalize it, can they produce negative body images. The mediate roles of appearance comparison and internalization of the thin-ideal in the results seem to illustrate this point. This study focuses on revealing this mediating mechanism.

For media attention, firstly, the results show that appearance comparison plays a fully mediating role between media attention and negative body image, that is, media attention can increase negative body image of college students through appearance comparison. This result proves the previous research that media attention will increase appearance comparison, and appearance comparison will lead to physical dissatisfaction. The network media provides convenience for the spread of ideal shape images conveniently and quickly. Actively and frequently comparing one's actual body image with the beautified images of others (i.e., comparing with someone who is stronger than himself) will lead individuals to pay more attention to their physical deficiencies, resulting in the negative idea that "others are better than me". According to the Upward Assimilation Theory (Collins,1996), people tend to compare with those who have stronger abilities and attributes than themselves, and that produce negative self-evaluation. Therefore, college students' attention to the perfect figure image in media information will make them make upward social comparison. People with higher social inclination are more likely to compare themselves with the image of "ideal thinness" spread in the media, and then produce more negative body images. The results are consistent with previous studies (Shroff \& Thompson, 2006), so hypothesis 3 was verified. This result shows that people exposed to more perfect body types in the media are more likely to produce appearance comparison, and then produce negative body images. Secondly, internalization of the thinideal plays a mediate role between media attention and negative body images. Specifically, the more information about ideal figure received by individuals from the mass media, the easier it is for them to internalize this information, that is, the higher the degree of internalization, the easier it is for individuals to be dissatisfied with their own bodies. This result is consistent with previous studies (Cattarin et al., 2000). This result shows that individuals who internalize the media's standard on body are more likely to produce negative body images.

In this study, it is found that individuals with high media attention tend to have higher comparative psychology, and their appearance comparison can predict the internalization of the thin-ideal of individuals, while individuals with high internalization are easily dissatisfied with their own figure (Jones, 2004). This mechanism is in line with Thompson's sociocultural model, and Hypothesis 7 was verified. This result shows that individuals who pay too much attention to the figure information in mass media are easy to have upward comparison motivation, that is, to compare their own figure with that of models or stars, and individuals who tend to internalize the high standard of the figure of stars or models into their own requirements. However, individuals often fail to achieve this standard and are dissatisfied with their body. To sum up, focusing only on media information will not produce negative body images, but individuals can produce negative body images through the internal mechanism of appearance comparison and internalization of the thin-ideal. 
For peer impact, firstly, this study also found that it can positively predict negative body images, and Hypothesis 2 was verified. "Social orientation is the way that Chinese people operate or adapt in their life circle (Yang, 2004)." Social orientation enables people to behave in accordance with social expectations, to gain approval from others and maintain interpersonal relationships. Under the influence of peer's appearance comments, college students demand themselves according to the social standards of figure, to obtain good interpersonal relationship and praise. It is found that the frequent talk about obesity in women's friendship groups is "self-derogatory" (Cruwys et al., 2016), and frequent participation in the talk about obesity will "enhance the negative experience of women's physical dissatisfaction" (Zhang, 2018). Further research shows that the more and more serious experiences of being laughed at by peers, the higher the individual's physical dissatisfaction and the more negative the body image (Michael et al., 2014). A study (Tucker et al.,2007) investigated the performance of women with different physical selfesteem in three different body image description groups, and found that among the peer groups that belittle each other, women have the lowest physical satisfaction. In addition, research have shown that women with negative physical selves are attention bias to negative appearance words, which may be alert and difficulty to escape (Kou et al., 2015). Therefore, the results of this study indicate that verbal interaction between peers about body size and weight aggravates individual dissatisfaction with body size.

Secondly, it is found that appearance comparison plays a mediate role between peer impact and negative body image. This result shows that individuals who receive more negative comments about body from peer groups, such as "so-and-so's legs in our class are so thin! My legs are so thick", due to the social and cultural pressure of negative comments, it is easier for them to compare with the perfect figure, and finally produce more negative body images. Under the Chinese cultural background, both male and female college students are influenced by friends or classmates around them, and they are very concerned about their evaluation of their figure, especially the negative evaluation, which will produce negative emotions and then negative physical knowledge of themselves. Similarly, internalization of the thin-ideal plays a mediate role between peer impact and negative body image, that is, the more peers talk or evaluate about body shape, the more individuals will internalize the standard of good body shape among peer groups, and this standard is difficult for individuals to achieve, so negative body image will increase. Previous studies have proved this point. One researcher found that found that internalization plays an mediate role between peer talks about appearance and physical satisfaction. Internalization, peer appearance criticism and BMI can directly predict the low physical satisfaction of female college students (Jones,2004).

Finally, Chinese college students are easily compared among peers when their friends and classmates talk about or evaluate too much about their weight, weight loss or appearance, thus internalizing others' definition of good figure and negatively evaluating their own figure. Hypothesis 8 was verified. Specifically, the bad talk or negative evaluation of body between peers or classmates will increase the comparative psychology of "good body" between college students and their peers, and then internalize the body standard of peers or society, which will discourage college students' self-confidence in the body, resulting in negative emotions and negative body images. 


\section{Strengths and Limitations}

This study offers several unique contributions. This study explored the effects of mass media and peer impact on negative body image and its partial mechanism. Taking Chinese college students as subjects, it further enriches Thompson's sociocultural model, which is of great significance for understanding the effects of mass media and peer impact on body image of college students and guiding them to form positive physical and mental health. First, too much discussion and evaluation of stature among peers will cause negative body images. Therefore, in order to reduce peer comments on each other's figure, college students should be guided to evaluate figures of themselves. There is no uniform standard for beauty, allowing the existence of various figure, and re-establishing students' definition of perfect figure. Second, too much comparison and internalization of appearance increases negative body images, so students should build up their self-confidence in their own figure, and form their own stable self-concept which will not be swayed by external standards at will, and appearance is not a standard for measuring a person's value. Third, it verifies the applicability of Thompson's sociocultural model in Chinese colleges.

There are also some shortcomings in this paper. Firstly, this study is a cross-sectional study, and it is impossible to determine the causal relationship among variables. In future studies, experimental methods can be used to increase the persuasiveness of the results. Secondly, the subjects selected in this study are college students, and future research can be extended to other age groups to explore the influence of mass media and peers on different age groups. Finally, this study only considers two mediate variables in Thompson's sociocultural model. Whether there is other variable that may affect negative body images remains to be discovered.

\section{Conclusions}

In summary, our research confirms the specific influence mechanism of media and peer factors on Chinese college students in the sociocultural model. The results show that peer impact has a direct impact on the negative body image of college students, but the influence of media attention on the negative body image of college students may not be direct. Instead, college students have a negative evaluation on their body through psychological activities such as appearance comparison and idealization. In addition, media attention and peer impact will further increase the negative evaluation of college students' figure through the chain mediation of "appearance comparison - internalization of the thin-ideal".

\section{Declarations}

\section{Ethics approval and consent to participate}

The studies involving human participants were reviewed and approved by the School of Education, Hunan University of Science and Technology.

Informed consent was obtained from all individual participants included in this study. 


\section{Consent for publication}

All authors agree to publish this manuscript.

\section{Availability of supporting data}

The datasets generated during and/or analyzed during the current study are available from the corresponding author on reasonable request.

\section{Competing interests}

The authors declare that they have no conflict of interest.

\section{Funding}

This work was supported by the National Social Science Fund of China (Research Special Project of University Ideological and Political Course) [grant number 19VSZ033]

\section{Authors' contributions}

All the authors conceived the study, JC designed this study and collected data. JS wrote this article and performed data analysis. XT and SB were mentoring the work on the article and revised this article. The authors read and approved the final manuscript.

\section{Acknowledgements}

First and foremost, I appreciate my country who give me a comfortable learning atmosphere. Second, I would like to show my deepest gratitude to my supervisor, Prof. Jinjun Chen, who has walked me through all the stages of the writing of this thesis. Without his illuminating instruction and patience, this thesis could not have reached its present form. I am also greatly indebted to all my teachers who have helped me to develop the fundamental and essential academic competence. My sincere appreciation also goes to all my classmates, who are my proud of my life. Last but not least, I want to thank all my friends, especially my three lovely roommates, for their encouragement and support.

\section{References}

1. Carlson Jones, D. (2004). Body Image Among Adolescent Girls and Boys: A Longitudinal Study. Developmental Psychology, 40(5), 823-835. https://doi.org/10.1037/0012-1649.40.5.823.

2. Cattarin, J. A., Thompson, J. K., Thomas, C., \& Williams, R. (2000). Body image, mood, and televised images of attractiveness: The role of social comparison. Journal of Social and Clinical Psychology, 19(2), 220-239. https://doi.org/10.1521/jscp.2000.19.2.220.

3. Chen, H., Gao, X., \& Jackson, T. (2007). Predictive models for understanding body dissatisfaction among young males and females in China. Behaviour Research and Therapy, 45(6), 1345-1356. 
https://doi.org/10.1016/j.brat.2006.09.015

4. Chen, H., Jackson, T., \& Huang, X. (2006). The Negative Physical Self Scale: Initial development and validation in samples of Chinese adolescents and young adults. Body Image, 3(4), 401-412. https://doi.org/10.1016/j.bodyim.2006.07.005

5. Collins, R. L. (1996). For better or worse: The impact of upward social comparison on selfevaluations. Psychological Bulletin, 119(1), 51-69. https://doi.org/10.1037/0033-2909.119.1.51

6. Crouch, A., \& Degelman, D. (1998). Influence of female body images in printed advertising on selfratings of physical attractiveness by adolescent girls. Perceptual and Motor Skills, 87(2), 585-586. https://doi.org/10.2466/pms.1998.87.2.585

7. Cruwys, T., Leverington, C.T., \& Sheldon,A.M. (2016). An experimental investigation of the consequences and social functions of fat talk in friendship groups. International Journal of Eating Disorders, 49(1), 84-91. https://doi.org/10.1002/eat.22446

8. Durkin, S.J., \& Paxton, S.J. (2002). Predictors of vulnerability to reduced body image satisfaction and psychological wellbeing in response to exposure to idealized female media images in adolescent girls. Journal of Psychosomatic Research, 53(5), 995-1005.https://doi.org/10.1016/S00223999(02)00489-0

9. Eisenberg, M.E., Neumark-Sztainer, D., Haines, J., \& Wall, M. (2006). Weight-teasing and emotional well-being in adolescents: Longitudinal findings from Project EAT. Journal of Adolescent Health, 38(6), 675-683. https://doi.org/10.1016/j.jadohealth.2005.07.002

10. Fredrickson,B.L., \& Roberts,T.-A.(1997). Objectification theory: Toward understanding women's lived experiences and mental health risks. Psychology of Women Quarterly, 21(2), 173-206. https://doi.org/10.1111/j.1471-6402.1997.tb00108.x

11. Gurari, I., Hetts, J.J., \& Strube, M.J. (2006). Beauty in the "I" of the Beholder: Effects of Idealized Media Portrayals on Implicit Self-image. Basic and Applied Social Psychology, 28(3), 273-282. https://doi.org/10.1207/s15324834basp2803_6

12. Haley J. Webb \& Melanie J. Zimmer-Gembeck.(2015).Body Image and Body Change Strategies Within Friendship Dyads and Groups: Implications for Adolescent Appearance-based Rejection Sensitivity. Social Development, 24(1),1-19. https://doi.org/10.1111/sode.12081

13. Huang, L.L, \& Zhang, J.H.(2005).Body Image and Its Predictors in Taiwan: Interpersonal Pressure and Media Agreement As Mediators. Chinese Journal of Psychology, 47(3), 269-

287.https://doi.org/10139656-200509-47-3-269-287-a

14. Huang, X.T., Chen, H., Fu, M.Q., \& Zeng, X. (2002). An Exploration into the Characters of Adolescent Students' Physical Self. Science of Psychology(3), 260-264.https://doi.org/10.3969/j.issn.16716981.2002.03.002

15. Jiang, M.Y.W., \& Vartanian, L.R. (2012). Attention and memory biases toward body-related images among restrained eaters. Body Image, 9(4), 503-509. https://doi.org/10.1016/j.bodyim.2012.06.007

16. Kou,H.,Su,Y.H.,Luo,X.C.,\& Chen,H.(2015).Attentional Bias Toward Face-related Words Among Females with Facial Negative Physical Self: Evidence from An Eye-movement Study.Acta Psychologica 
Sinica, 47(10),1213-1222. https://doi.org/10.3724/SP.J.1041.2015.01213

17. Lawler, M., \& Nixon, E. (2011). Body dissatisfaction among adolescent boys and girls: The effects of body mass, peer appearance culture and internalization of appearance ideals. Journal of Youth and Adolescence, 4O(1), 59-71. https://doi.org/10.1007/s10964-009-9500-2

18. Liu, X.H.(2021). The influence of fat talk on female college students' negative physical self. Journal of Campus Life, 19(03), 251-254.https://doi.org/ 10.19521/J.Cnki.1673-1662.2021.03.016.

19. Liu, D.Q. (2009). Body Image in Chinese College Students: Mass Media and Peer Influences. (Doctoral dissertation, Xiamen University). https://doi.org/CNKI:CDMD:2.2009.189723

20. Michael, S. L., Wentzel, K., Elliott, M. N., Dittus, P. J., Kanouse, D. E., Wallander, J. L., Pasch, K. E., Franzini, L., Taylor, W. C., Qureshi, T., Franklin, F. A., \& Schuster, M. A. (2014). Parental and peer factors associated with body image discrepancy among fifth-grade boys and girls. Journal of Youth and Adolescence, 43(1), 15-29. https://doi.org/10.1007/s10964-012-9899-8

21. Myers, P. N., \& Biocca, F. A. (1992). The elastic body image: The effect of television advertising and programming on body image distortions in young women. Journal of Communication, 42(3), 108133. https://doi.org/10.1111/j.1460-2466.1992.tb00802.x

22. Rodgers, R.F., \& DuBois, R.H. (2016). Cognitive biases to appearance-related stimuli in body dissatisfaction: A systematic review. Clinical Psychology Review, 46, 1-11. https://doi.org/10.1016/j.cpr.2016.04.006

23. Shroff, H., \& Thompson, J. K. (2006). The tripartite influence model of body image and eating disturbance: A replication with adolescent girls. Body Image, 3(1), 17-23. https://doi.org/10.1016/j.bodyim.2005.10.004

24. Stice, E., Schupak-Neuberg, E., Shaw, H. E., \& Stein, R. I. (1994). Relation of media exposure to eating disorder symptomatology: An examination of mediating mechanisms. Journal of Abnormal Psychology, 103(4), 836-840. https://doi.org/10.1037/0021-843X.103.4.836

25. Stice, E., Ziemba, C., Margolis, J., \& Flick, P. (1996). The dual pathway model differentiates bulimics, subclinical bulimics, and controls: Testing the continuity hypothesis. Behavior Therapy, 27(4), 531549. https://doi.org/10.1016/S0005-7894(96)80042-6

26. Striegel-Moore, R.H., \& Bulik, C.M. (2007). Risk factors for eating disorders. American Psychologist, 62(3), 181.https://doi.org/10.1111/j.1749-6632.1997.tb48199.x

27. Tang,L.Y.(2010).Mass Media and Female Body Image.(Doctoral dissertation,Shanghai Jiaotong University).https://doi.org/CNKI:CDMD:2.2010.206795

28. Thompson, J. K., Heinberg, L. J., Altabe, M., \& Tantleff-Dunn, S. (1999). Exacting beauty: Theory, assessment, and treatment of body image disturbance. American Psychological Association,54(1),131-132. https://doi.org/10.1037/10312-000

29. Thompson, J. K., van den Berg, P., Roehrig, M., Guarda, A. S., \& Heinberg, L. J. (2004). The Sociocultural Attitudes Towards Appearance Scale-3 (SATAQ-3): Development and Validation. International Journal of Eating Disorders, 35(3), 293-304. https://doi.org/10.1002/eat.10257 
30. Tiggemann, M., \& Slater, A. (2004). Thin Ideals in Music Television: A Source of Social Comparison and Body Dissatisfaction. International Journal of Eating Disorders, 35(1), 48-58.

https://doi.org/10.1002/eat.10214

31. Tucker, K. L., Martz, D. M., Curtin, L. A., \& Bazzini, D. G. (2007). Examining "fat talk" experimentally in a female dyad: How are women influenced by another woman's body presentation style? Body Image, 4(2), 157-164. https://doi.org/10.1016/j.bodyim.2006.12.005

32. Uusberg, H., Peet, K., Uusberg, A., \& Akkermann, K. (2018). Attention biases in preoccupation with body image: An ERP study of the role of social comparison and automaticity when processing body size. Biological Psychology, 135, 136-148. https://doi.org/10.1016/j.biopsycho.2018.03.007

33. Wu, S.S., Lv, Z.Y., Chen, H., Wang, Y.H., \& Xiao, Z.L. (2016). Fat talk A psychological communication.Advances in Psychological Science, 24(1), 111119.https://doi.org/10.3724/SP.J.1042.2016.00111

34. Xing, S.F., \& Yu, G.L.(2005).A Review on Research of Social Comparison. Advances in Psychological Science, 13(1):78-84.https://doi.org/ 10.3969/j.issn.1671-3710.2005.01.012

35. Xiong, H.X., Zhang, J., Ye, B.J.,Zheng, X.,\& Sun,P.Z.(2012). Common Method Variance Effects and the Models of Statistical Approaches for Controlling It. Advances in Psychological Science, 20(05), 757769.https://doi.org/10.3724/SP.J.1042.2012.00757

36. Yang, X.Y. (2007). The Influence of the Mass Media on Women's body image: A Exploration of Social Comparison Trait and Mode. (Doctoral dissertation, Southwest University). https://doi.org/10.7666/d.y1074625

37. Yang,G.S. (2004). Chinese Psychology and Behavior: A Localization Study.Renmin University of China Press.

38. Zhang,L.(2018). The Effect of Female College Students' Fat Talk on Body Dissatisfaction:The Moderating Effect of Self-compassion.(Doctoral dissertation, Henan University).

\section{Figures}

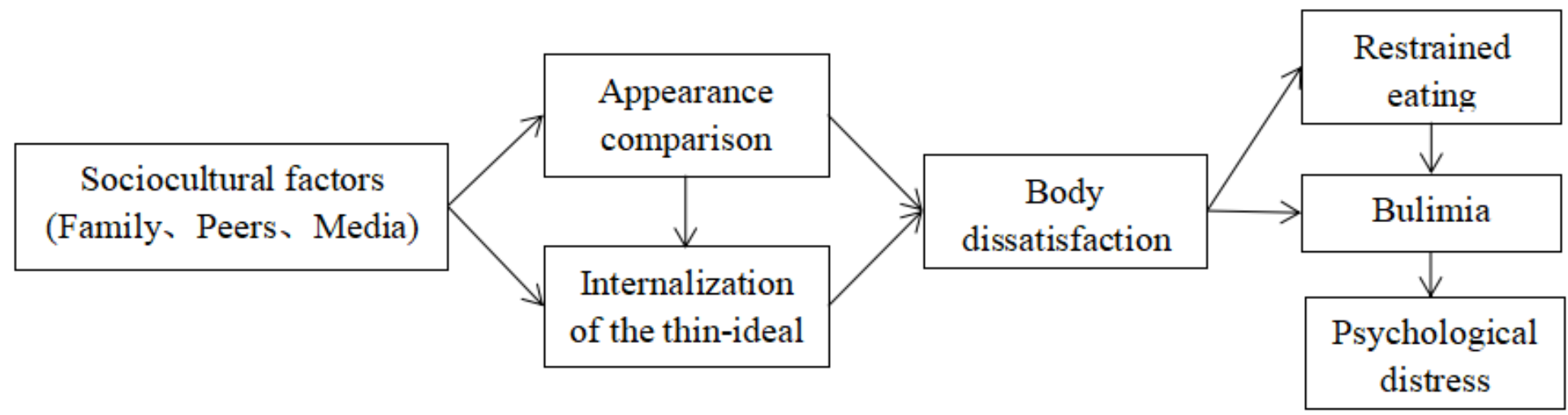

Figure 1 


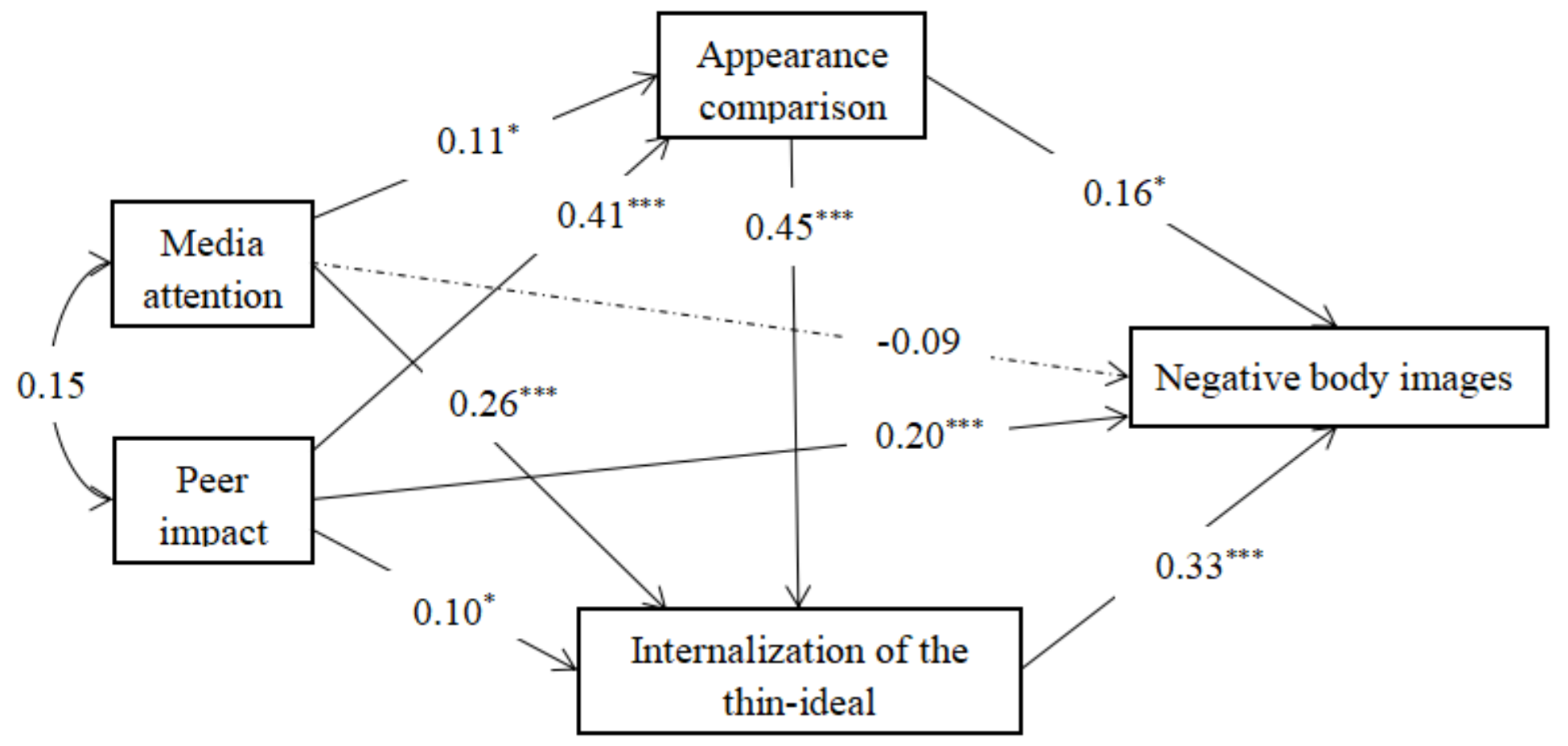

Figure 2

Multiple Intermediary Models of Appearance Comparison and Internalization of the Thin-ideal Note. Standardized regression weights are reported. Nonsignificant paths are depicted by dotted lines. *p $₫ 0.05 \rrbracket$

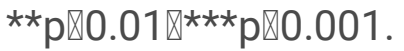

